\title{
STUDIES ON STARLING'S LAW OF THE HEART. I. THE CIRCULATORY RESPONSE TO ACUTE HYPERVOLEMIA AND ITS MODIFICATION BY GANGLIONIC BLOCKADE
}

\author{
By ROBERT L. FRYE AND EUGENE BRAUNWALD With THE TECHNICAL ASSISTANCE OF \\ ESTELLE R. COHEN
}

(From the Section of Cardiology, Clinic of Surgery, National Heart Institute, Bethesda, Md.)

(Submitted for publication January 21, 1960; accepted March 4, 1960)

The application of Starling's law of the heart to the circulation of man has been the subject of intensive interest and investigation. Infusions of intravenous fluids have been employed in attempts to simulate in man the increase in venous return to the Starling heart-lung preparation. A variety of fluids has been utilized in such studies in man, including saline (1-4), dextran (4-6), glucose solutions (4), and human serum albumin $(2,7)$. In general, the results have been conflicting, with a few investigators noting an increase both in filling pressure and cardiac output $(1,5)$, while in the majority of studies no consistent relationship between these parameters was noted $(2-4,6,7)$. Indeed, in most human subjects the augmentation of the total blood volume has failed to be associated with a rise in cardiac output, even in the face of a decline in hematocrit $(2-4,6,7)$. The possibility was considered that the presence of an actively functioning autonomic nervous system in the intact state and its absence in the heart-lung preparation accounts for the difference in the cardiac response to infusion in man and increased venous return to the heart-lung preparation. The present study was therefore designed to determine whether the circulatory response to acutely induced hypervolemia is modified by reducing the activity of the autonomic nervous system by means of ganglionic blockade.

\section{METHODS}

Seven male subjects with normal cardiovascular systems were studied. They ranged in age from 17 to 39 years and averaged 27 years. The subjects were studied following complete recovery from an acute illness unrelated to the cardiovascular system. Each individual was subjected to three phlebotomies over a period of approximately 10 days and the $1,500 \mathrm{ml}$ of blood so obtained was stored in solutions of sodium citrate, citric acid and dextrose. Approximately two days after the third phlebotomy the first study was carried out. Cardiac output, heart rate, and arterial pressure were recorded, generally in duplicate, immediately before the blood which had been removed was returned. The $1,500 \mathrm{ml}$ transfusion was given at a rate of $19.3 \mathrm{ml}$ per minute utilizing a Bowman infusion pump. Measurements were again carried out immediately following completion of the transfusion and were usually repeated 15 minutes later. Following another series of phlebotomies over a period of approximately 5 days, the procedure was repeated in an identical manner except that the circulatory effects of transfusion were now studied after partial ganglionic blockade had first been induced and while it was maintained through the entire period of observation. In two subjects, H. S. and R. W., the experimental sequence was reversed and the circulatory responses to transfusion were first studied in the presence of ganglionic blockade and the effects of transfusion without blockade were determined at the time of the second study. All observations were carried out with the subjects in the recumbent position, in the postabsorptive state after receiving 100 mg pentobarbital intramuscularly approximately one hour before study.

The ganglionic blockade was induced by a constant, continuous intravenous infusion of Arfonad, a thiophanium derivative ( $d-3,4\left[1^{\prime}, 3^{\prime}\right.$-dibenzyl-2'-keto-imidazolido] -1,2trimethylene thiophanium $d$-camphorsulfonate), a drug which also has some direct vasodilatory action $(8,9)$. Arfonad was administered by means of an infusion pump at a rate which ranged from 1.0 to $10.4 \mathrm{mg}$ per minute with an average rate of $4.0 \mathrm{mg}$ per minute. The specific infusion rate chosen for each subject was that which lowered systolic arterial pressure by approximately 40 $\mathrm{mm} \mathrm{Hg}$ and this rate was maintained constant for the entire study. The actual decline of systolic arterial pressure ranged from 32 to $55 \mathrm{~mm} \mathrm{Hg}$ with an average of $43 \mathrm{~mm} \mathrm{Hg}$. Arterial pressure was measured through an indwelling needle with a Statham pressure transducer and recorded, together with the electrocardiogram and the indicator dilution curves, on a multichannel photographic recorder.

Cardiac output was determined by the indicator dilution technic and calculated in the manner described by Hamilton, Moore, Kinsman and Spurling (10). Evans blue dye was injected from a tared syringe through a $75 \mathrm{~cm}$ polyethylene catheter ( $\mathrm{PE}$ no. $50,0.58 \mathrm{~mm}$ ID) introduced percutaneously through an antecubital vein 
TABLE I

Hematocrits of subjects studied

\begin{tabular}{|c|c|c|c|c|c|}
\hline \multirow[b]{2}{*}{ Subj. } & \multirow[b]{2}{*}{$\begin{array}{l}\text { Hct. prior to } \\
\text { phlebotomy }\end{array}$} & \multicolumn{2}{|c|}{ Initial study } & \multicolumn{2}{|c|}{ Second study } \\
\hline & & $\underset{\text { beginning }}{\text { Hct. at }}$ & $\begin{array}{l}\text { Hct. at } \\
\text { completion }\end{array}$ & $\begin{array}{c}\text { Hct. at } \\
\text { beginning }\end{array}$ & $\begin{array}{l}\text { Hct. at } \\
\text { completion }\end{array}$ \\
\hline C. B. & 47.5 & 39.9 & 38.0 & 38.5 & 39.5 \\
\hline H. L. & & 37.0 & 35.5 & 35.0 & 39.0 \\
\hline M. J. & 46.0 & 34.0 & 38.0 & 32.0 & 36.0 \\
\hline M. Z. & 44.0 & 34.0 & 34.5 & 33.5 & 35.0 \\
\hline H. S. ${ }^{*}$ & 35.0 & 32.0 & 35.0 & 32.0 & 37.0 \\
\hline E. B. & 45.5 & 37.0 & 38.0 & 37.0 & 38.0 \\
\hline R. W.* & 43.0 & 31.0 & 35.2 & 29.0 & 34.0 \\
\hline Avg. & 43.5 & 35.0 & 36.3 & 33.9 & 36.9 \\
\hline
\end{tabular}

* Subjects in whom transfusion was given first in the presence of ganglionic blockade.

into the superior vena cava or right atrium. Arterial blood was sampled through an indwelling arterial needle and pulled through a cuvet densitometer $(11,12)$ by a motor driven syringe at a rate of $20 \mathrm{ml}$ per minute. The response of the densitometer to a sudden change in density is 95 per cent in one second and over 99 per cent in two seconds (13). The volume of the connecting tube from the arterial needle to the densitometer was $0.41 \mathrm{ml}$; the time required for the blood to traverse this tubing (1.23 seconds) was subtracted from the observed mean circulation time in calculating the actual mean circulation time. The validity of the technics employed in the measurement of the cardiac output and central blood volume had first been demonstrated by a comparison with direct measurements in a circulatory model (14) and by flowmeter measurements in the openchest dog over a wide range of flow rates (15).
In the present study 23 of the 28 measurements of cardiac output were carried out in duplicate, 10 to 15 minutes apart. The standard error of the 23 duplicate determinations of cardiac output was $493 \mathrm{ml}$ per minute. Central blood volume, that is, the volume of blood between the site of injection in the vena cava or right atrium and the site of sampling in the systemic artery, as well as all temporally equidistant points, was calculated from the formula: $\mathrm{CBV}=\frac{\mathrm{MCT} \times \mathrm{C} \text {.O. }}{60}$ where $\mathrm{CBV}=$ central blood volume in liters, $\mathrm{MCT}=$ mean circulation time in seconds and C.O. = cardiac output in liters per minute. The standard error of 23 duplicate determinations of the central blood volume was $115 \mathrm{ml}$. The average of the two cardiac output and central blood volume determinations is presented in Table II in the 23 of the 28 determinations in which they were carried out.

TABLE II

Hemodynamic data obtained before and after transfusion in the absence and presence of ganglionic blockage*

\begin{tabular}{|c|c|c|c|c|c|c|c|c|c|c|c|c|c|}
\hline \multirow[b]{2}{*}{$\begin{array}{l}\text { Subj. } \\
\text { BSA }\end{array}$} & \multirow[b]{2}{*}{ Condition } & \multicolumn{2}{|c|}{ C. $\mathrm{O}$. } & \multicolumn{2}{|c|}{ MAP } & \multicolumn{2}{|c|}{ SV } & \multicolumn{2}{|c|}{ CBV } & \multicolumn{2}{|c|}{ MWLV } & \multicolumn{2}{|c|}{ SWLV } \\
\hline & & $\begin{array}{c}\text { Avg. } \\
\text { before }\end{array}$ & $\begin{array}{l}\text { Avg. } \\
\text { after }\end{array}$ & $\begin{array}{l}\text { Avg. } \\
\text { before }\end{array}$ & $\begin{array}{l}\text { Avg. } \\
\text { after }\end{array}$ & $\begin{array}{l}\text { Avg. } \\
\text { before }\end{array}$ & $\begin{array}{l}\text { Avg. } \\
\text { after }\end{array}$ & $\begin{array}{l}\text { Avg. } \\
\text { before }\end{array}$ & $\begin{array}{l}\text { Avg. } \\
\text { after }\end{array}$ & $\begin{array}{l}\text { Avg. } \\
\text { before }\end{array}$ & $\begin{array}{l}\text { Avg. } \\
\text { af ter }\end{array}$ & $\begin{array}{l}\text { Avg. } \\
\text { before }\end{array}$ & $\begin{array}{l}\text { Avg. } \\
\text { after }\end{array}$ \\
\hline C. B. & C & $8.97 \dagger$ & $7.80 \dagger$ & $78 \dagger$ & $83 \dagger$ & $100 \dagger$ & $78 \dagger$ & & & $10.03 \dagger$ & $9.30 \dagger$ & $111.4 \dagger$ & $93.0 \dagger$ \\
\hline 1.86 & $\mathrm{~A}$ & 7.03 & 9.67 & 75 & 84 & 69 & 108 & & & 7.55 & 11.63 & 73.9 & 129.2 \\
\hline H. L. & $\mathrm{C}$ & 6.19 & 6.40 & 109 & 120 & 97 & 92 & 1.67 & 1.49 & 9.69 & 11.00 & 152.0 & 157.1 \\
\hline 1.86 & A & 6.47 & $8.11 \dagger$ & 83 & $116 \dagger$ & 83 & $101 \dagger$ & 1.99 & $2.20 \dagger$ & 7.72 & $13.09 \dagger$ & 97.7 & $163.6 \dagger$ \\
\hline M. J. & $\mathrm{C}$ & 5.41 & 8.47 & 78 & 103 & 128 & 146 & 1.44 & 1.57 & 5.98 & 12.51 & 139.2 & 214.6 \\
\hline 1.90 & A & 5.57 & 8.83 & 72 & 106 & 62 & 116 & 1.07 & 1.48 & 5.74 & 13.51 & 65.6 & 176.5 \\
\hline M. Z. & C & 5.52 & 4.93 & 115 & 123 & 81 & 72 & 1.38 & 1.33 & 8.92 & 8.67 & 129.3 & 124.8 \\
\hline 1.92 & A & 4.25 & 6.52 & 73 & 105 & 56 & 80 & 1.05 & 1.38 & 4.49 & 9.88 & 58.6 & 122.0 \\
\hline H.S. $\neq$ & C & 6.22 & 6.82 & 83 & 122 & 82 & 73 & 1.20 & 1.07 & 7.42 & 11.90 & 97.6 & 130.6 \\
\hline 1.68 & A & 4.78 & 6.89 & 62 & 93 & 49 & 72 & 0.62 & 0.90 & 4.24 & 9.12 & 42.9 & 95.6 \\
\hline E. B. & C & 6.03 & 7.27 & 82 & 90 & 78 & 86 & 1.43 & 1.55 & 7.06 & 9.39 & 91.2 & 110.7 \\
\hline 1.86 & A & 5.03 & 6.85 & 55 & 88 & 53 & 76 & 1.18 & 1.35 & 3.87 & 8.63 & 41.4 & 96.5 \\
\hline R. W. & C & 6.31 & 6.46 & 69 & 102 & 103 & 106 & 1.50 & 1.56 & 6.22 & 9.42 & 101.9 & 154.9 \\
\hline & A & 6.25 & 9.33 & 56 & 93 & 76 & 127 & 1.17 & 1.86 & 4.98 & 12.40 & 60.1 & 169.7 \\
\hline & & 6.38 & 6.88 & 88 & 106 & 96 & 93 & 1.44 & 1.43 & 7.90 & 10.31 & 117.5 & 140.8 \\
\hline Avg. & A & 5.63 & 8.03 & 68 & 98 & 64 & 97 & 1.18 & 1.53 & 5.51 & 11.18 & 62.9 & 136.2 \\
\hline
\end{tabular}

* BSA = body surface area in $\mathrm{m}^{2} ; \mathrm{C}=$ control study; $\mathrm{A}=$ transfusion in presence of Arfonad infusion; $\mathrm{C}$. O. = cardiac output in $\mathrm{L} / \mathrm{min} ; \mathrm{MAP}=$ mean arterial pressure in $\mathrm{mm} \mathrm{Hg} ; \mathrm{SV}=$ stroke volume in $\mathrm{ml} ; \mathrm{CBV}=\mathrm{central}$ blood volume in liters; $M W L V=$ minute work of left ventricle in $\mathrm{kg}-\mathrm{m} / \mathrm{min}$; SWLV = stroke work of left ventricle in grammeters.

† Single determinations.

† Subjects in whom transfusion was given first in presence of ganglionic blockade. 
The following formula was utilized to calculate the work of the left ventricle:

$$
M W L V=\frac{\text { MAP } \times 1.055 \times \text { C.O. }}{1,000}
$$

where $M W L V=$ minute work left ventricle in kilogrammeters per minute, MAP $=$ mean arterial pressure in centimeters of $\mathrm{H}_{2} \mathrm{O}, 1.055$ = specific gravity of blood and C.O. = cardiac output in liters per minute.

Again, the average of the two cardiac output determinations was utilized, when available, in these calculations. The statistical analysis is based upon a comparison of the standard deviations of the mean differences in response to transfusion carried out in the absence and in the presence of ganglionic blockade.

\section{RESULTS}

Mild anemia was induced by the phlebotomies. The hematocrit values obtained prior to phlebotomy, before, and after both transfusions are presented in Table I. The results of the pertinent

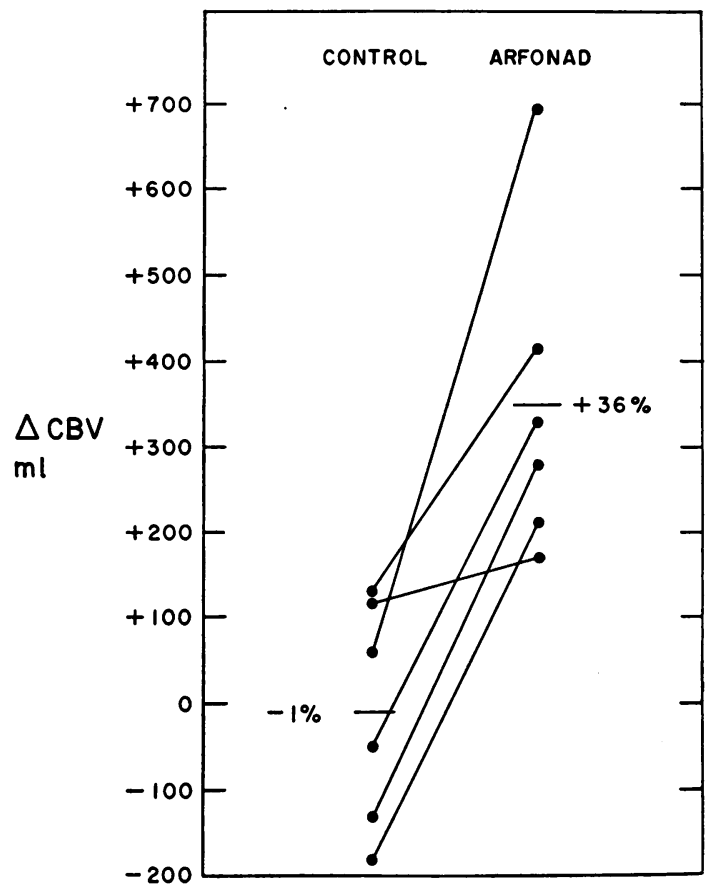

Fig. 1. EFFECT OF ACUTE HYPERVOLEMIa ON CENTRAL BLOOD volume. The solid circles on the left represent the changes in central blood volume produced by the transfusion in the absence of ganglionic blockade. On the right are represented the changes in central blood volume produced by transfusion during ganglionic blockade by Arfonad. The lines between the circles connect observations made on the same subject. The horizontal bar represents the mean change for all subjects and the mean percentage change resulting from transfusion is recorded beside the horizontal bar.

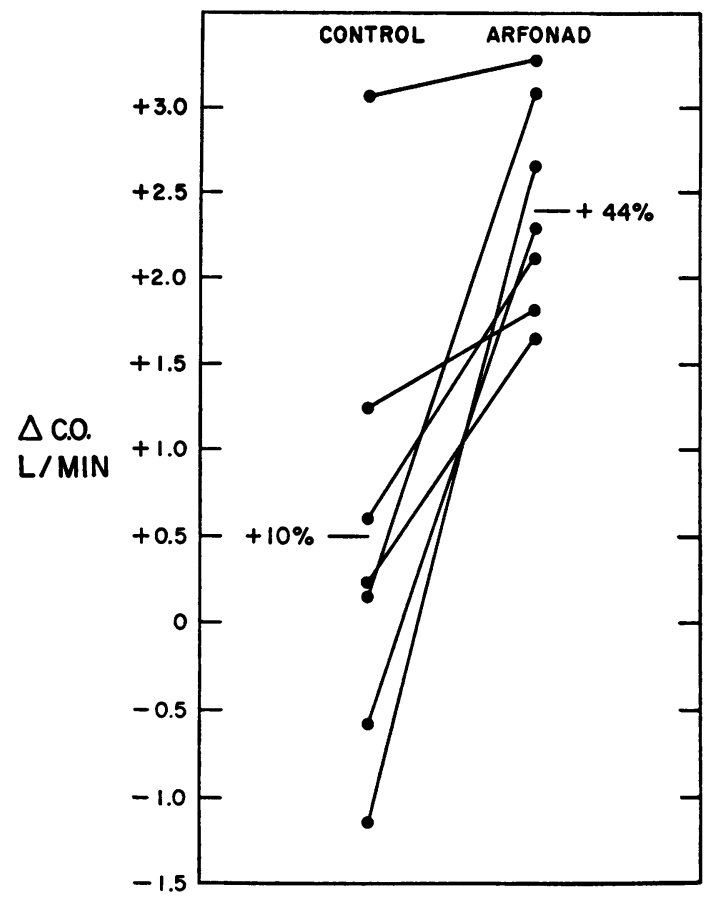

Fig. 2. EFFECT OF ACUTE HYPERVOLEMIA ON CARDIAC OUTPUT.

hemodynamic measurements are presented in Table II.

Figure 1 demonstrates the effect of the transfusion on the central blood volume during the control study and in the presence of partial ganglionic blockade. During the control study the change in central blood volume ranged from -180 to $+130 \mathrm{ml}$ and averaged $-8 \mathrm{ml}$, representing an average decline of 1 per cent. In the presence of ganglionic blockade the change in central blood volume ranged from +170 to $+690 \mathrm{ml}$ and averaged $+350 \mathrm{ml}$, representing a mean increase of 36 per cent. In each subject the central blood volume rose to a greater extent when transfusion was carried out in the presence of partial ganglionic blockade than in its absence. This difference in response to blood transfusion was statistically significant $(p<0.01)$.

The effect of the transfusion on the cardiac output during the control study and in the presence of Arfonad infusion is represented in Figure 2. During the control study the change in the cardiac output ranged from -1.17 to $+3.06 \mathrm{~L}$ per minute and averaged $+0.50 \mathrm{~L}$ per minute, representing a mean increase of 10 per cent. In the presence of partial ganglionic blockade the change in cardiac 


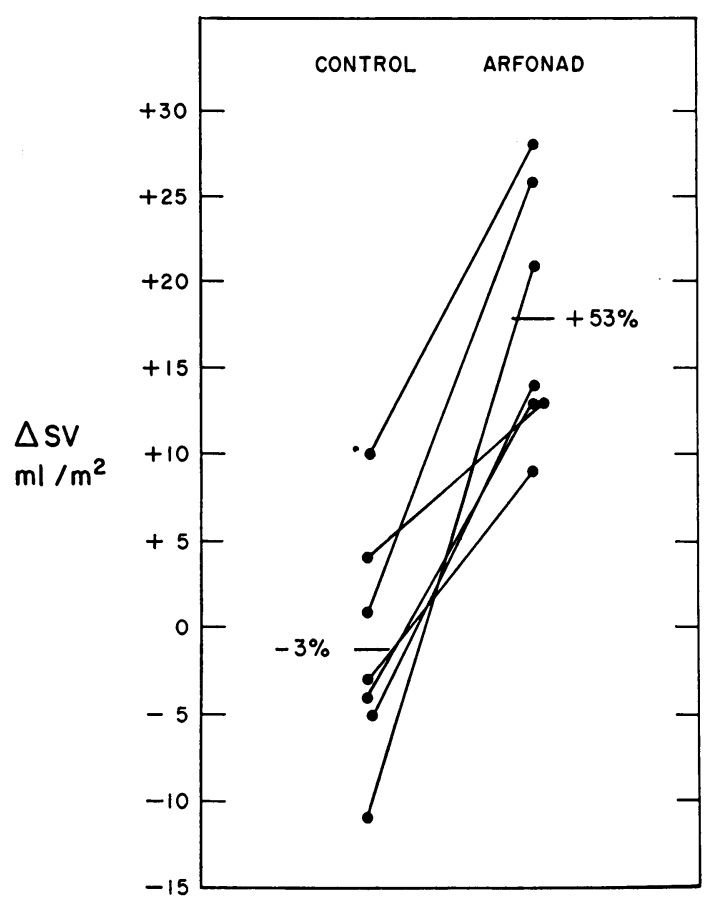

Fig. 3. EFFECT of ACUTE hypervolemia on STROKE VOLUME.

output ranged from +1.64 to $+3.26 \mathrm{~L}$ per minute and averaged $+2.40 \mathrm{~L}$ per minute, representing a mean increase in cardiac output of 44 per cent. In each subject the cardiac output rose to a greater extent when transfusion was carried out in the presence of partial ganglionic blockade than in its absence. This difference in response to transfusion was statistically significant $(\mathrm{p}<0.01)$.

Figure 3 illustrates the change in stroke volume index induced by the transfusion in the absence and in the presence of partial ganglionic blockade. During the control study the change in stroke volume index ranged from -11 to $+10 \mathrm{ml}$ per $\mathrm{m}^{2}$ and averaged $-1 \mathrm{ml}$ per $\mathrm{m}^{2}$, representing a mean decrease of 3 per cent. In the presence of partial ganglionic blockade the increase in the stroke volume index ranged from 9.3 to $28 \mathrm{ml}$ per $\mathrm{m}^{2}$ and averaged $18 \mathrm{ml}$ per $\mathrm{m}^{2}$, representing a mean increase of 53 per cent. In each subject the stroke volume index rose to a greater extent when transfusion was carried out in the presence of partial ganglionic blockade than in its absence. This difference in response to transfusion was statistically significant $(\mathrm{p}<0.01)$.

In the control study before transfusion, the systolic arterial pressure ranged from 90 to 156 $\mathrm{mm} \mathrm{Hg}$ with an average of $118 \mathrm{~mm} \mathrm{Hg}$; the diastolic arterial pressure ranged from 53 to $78 \mathrm{~mm}$ $\mathrm{Hg}$ with an average of $61 \mathrm{~mm} \mathrm{Hg}$. Following transfusion in the control study, the systolic arterial pressure ranged from 117 to $176 \mathrm{~mm} \mathrm{Hg}$ and averaged $143 \mathrm{~mm} \mathrm{Hg}$; the diastolic arterial pressure ranged from 62 to $86 \mathrm{~mm} \mathrm{Hg}$ and averaged $76 \mathrm{~mm} \mathrm{Hg}$.

In the study carried out during Arfonad infusion, before transfusion the systolic arterial pressure ranged from 71 to $95 \mathrm{~mm} \mathrm{Hg}$ and averaged $84 \mathrm{~mm} \mathrm{Hg}$; the diastolic arterial pressure ranged from 39 to $57 \mathrm{~mm} \mathrm{Hg}$ and averaged $49 \mathrm{~mm} \mathrm{Hg}$. Following the transfusion in the studies performed during Arfonad infusion, the systolic arterial pressure ranged from 107 to $151 \mathrm{~mm} \mathrm{Hg}$ and averaged $128 \mathrm{~mm} \mathrm{Hg}$; the diastolic arterial pressure ranged from 65 to $92 \mathrm{~mm} \mathrm{Hg}$ with an average of $75 \mathrm{~mm}$ $\mathrm{Hg}$.

The change in mean systemic arterial pressure induced by transfusion in the absence and in the presence of partial ganglionic blockade is illustrated in Figure 4. During the control study the increment in mean systemic arterial pressure ranged from 5 to $39 \mathrm{~mm} \mathrm{Hg}$ and averaged $18 \mathrm{~mm}$ $\mathrm{Hg}$, representing a mean increase of 23 per cent. In the presence of partial ganglionic blockade the increase in mean systemic arterial pressure ranged

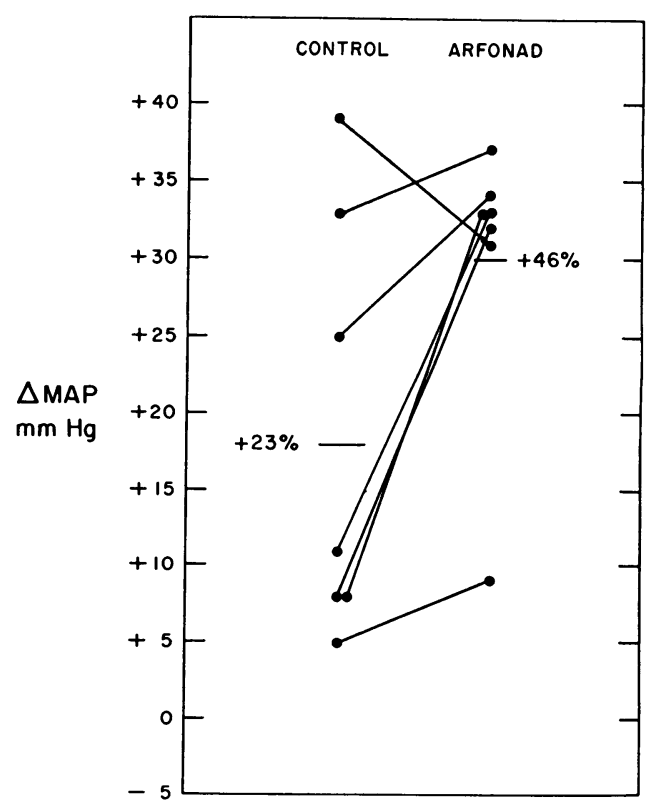

Fig. 4. EFfect of acute hypervolemia on MEAN SYSTEMIC ARTERIAL PRESSURE. 
from 9 to $37 \mathrm{~mm} \mathrm{Hg}$ and averaged $+30 \mathrm{~mm} \mathrm{Hg}$, representing a mean increase of 46 per cent. In six of the seven subjects the arterial pressure rose more in the presence of partial ganglionic blockade than in its absence. This difference in response to the transfusion was statistically significant $(\mathrm{p}<0.15)$.

Figure 5 depicts the change in left ventricular minute work induced by the transfusion in the control study and in the presence of partial ganglionic blockade. During the control study the change in left ventricular minute work ranged from -0.39 to $+3.43 \mathrm{~kg}-\mathrm{m}$ per minute per $\mathrm{m}^{2}$ and averaged $+1.31 \mathrm{~kg}-\mathrm{m}$ per minute per $\mathrm{m}^{2}$, representing a mean increase of 37 per cent. In the presence of partial ganglionic blockade the increase in left ventricular minute work ranged from 2.19 to $4.09 \mathrm{~kg}-\mathrm{m}$ per minute per $\mathrm{m}^{2}$ and averaged $3.03 \mathrm{~kg}-\mathrm{m}$ per minute per $\mathrm{m}^{2}$, representing a mean increase of 111 per cent. In each subject the left ventricular minute work rose to a greater extent when transfusion was carried out in the presence of partial ganglionic blockade than in its absence. The difference in response to transfusion was statistically significant $(\mathrm{p}<$ 0.01 ).

Figure 6 illustrates the change in left ventricular stroke work induced by the transfusion in the control study and in the presence of partial gang-

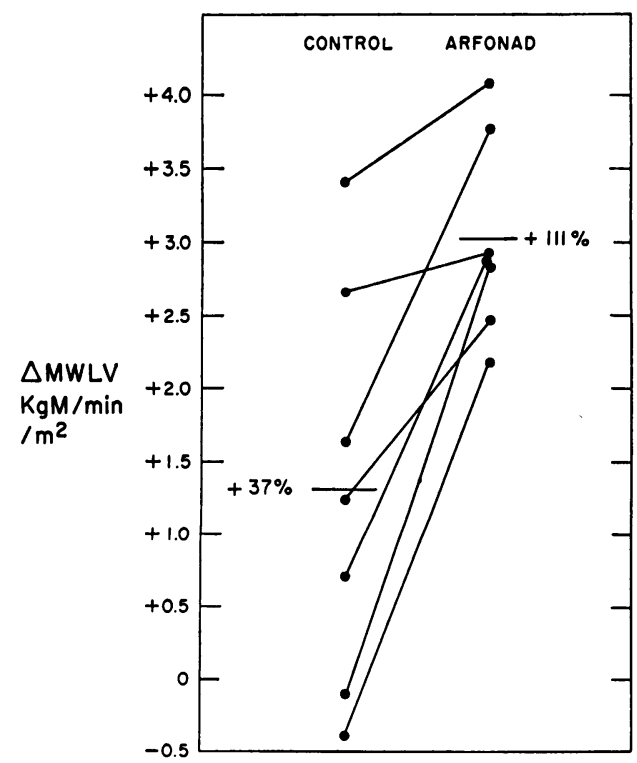

Fig. 5. EFFECT OF ACUTE HYPERVOLEMIA ON LEFT VENTRICULAR MINUTE WORK.

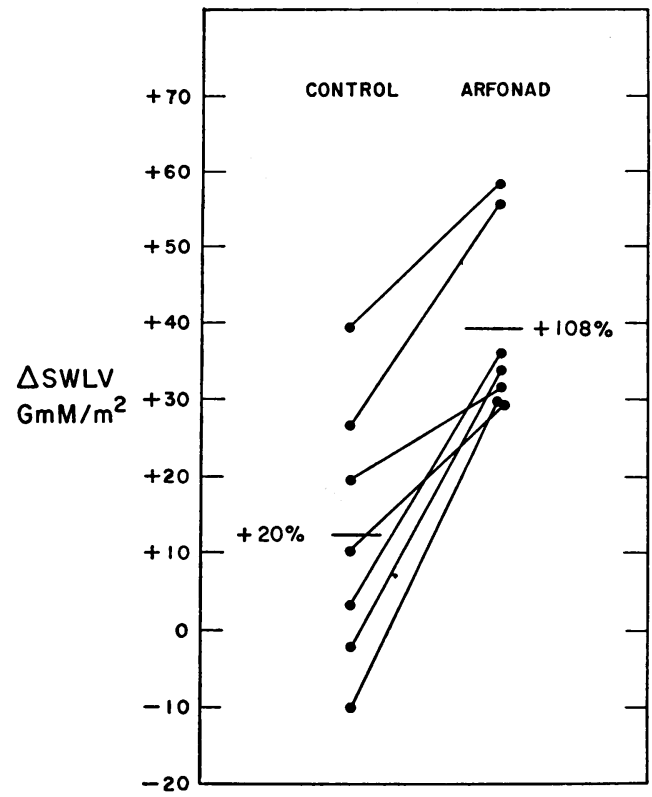

Fig. 6. EFfect of ACUTE hypervolemia on Left VENTRICULAR STROKE WORK.

lionic blockade. During the control study the change in left ventricular stroke work ranged from -9.9 to $+39.5 \mathrm{~g}-\mathrm{m}$ per $\mathrm{m}^{2}$ and averaged $+12.6 \mathrm{~g}-\mathrm{m}$ per $\mathrm{m}^{2}$, representing a mean increase of 20 per cent. In the presence of partial ganglionic blockade the change in left ventricular stroke work ranged from +29 to $58.4 \mathrm{~g}-\mathrm{m}$ per $\mathrm{m}^{2}$ and averaged $39.16 \mathrm{~g}-\mathrm{m}$ per $\mathrm{m}^{2}$, representing a mean increase of 108 per cent. In each subject the left ventricular stroke work rose to a greater extent when transfusion was carried out in the presence of partial ganglionic blockade than in its absence. The difference in response to transfusion was statistically significant $(p<0.01)$.

\section{DISCUSSION}

The response of cardiac output to transfusion in the control studies reported herein is in agreement with the findings of those investigators (2$4,6,7)$ who have observed that the cardiac output is neither increased consistently by large intravenous infusions, nor decreased by venesection of 300 to $900 \mathrm{ml}$ or by the trapping of blood in the extremities (16). In the absence of Arfonad infusion, the large transfusion was not associated with a significant increase in central blood volume. Failure of the central blood volume to increase following large infusions of dextran was also 
noted in the dog by Milnor and Bertrand (17). In the presence of the partial ganglionic blockade and the vasodilatation induced by the Arfonad, blood transfusion resulted in a substantial increase in central blood volume which was associated with a striking increase in the output and work of the left ventricle. The important role of the central blood volume as a determinant of cardiac output, particularly when the latter is initially low, has been suggested previously $(18,19)$ and the data presented herein are consistent with this concept.

This difference in the response of the central blood volume to the transfusion in the absence and in the presence of Arfonad infusion may help to explain the failure of a consistent augmentation of the cardiac output following the acute expansion of total blood volume in the intact state. One may speculate that during the "control" portion of this study and in experiments reported by others $(2-4,6,7,17)$, this expansion of blood volume increased intravascular pressure. The consequent stimulation of arterial (20) and systemic venous baroreceptors (21) could have resulted in a decrease in venous tone resulting in an increased capacity of the venous bed at any given transmural pressure (21-24). This decrease in venous tone, in turn, could result in a tendency for the infused fluid to pool in the systemic venous bed, which would minimize any augmentation of the volume of blood in the heart and lungs (25). Accordingly, a smaller increase in cardiac output and ventricular work occurs than would be expected in the absence of such reflex venodilatation. However, since no measurements of peripheral venous pressure were carried out, this explanation must be considered to be speculative. Furthermore, it is now clear from the experiments of Daly and Luck (26) and of Sarnoff and co-workers (27) that carotid sinus stimulation depresses ventricular function strikingly and thereby diminishes the external work performed by the ventricle from any given filling pressure. In addition, the latter workers have also shown that baroreceptor stimulation depresses atrial contractility. In this manner the contribution of atrial contraction to ventricular filling is diminished and the ventricular stroke work for any given level of mean atrial pressure is further decreased (28). Finally, by inducing reflex arteriolar dilatation, baroreceptor stimulation would tend to diminish further any increase in ventricular work induced by hypervolemia.

It was observed, however, that during the infusion of Arfonad, the blood transfusion resulted in substantial augmentation of the output and work of the left ventricle. It is postulated that as a consequence of the partial ganglionic blockade induced by Arfonad, venous tone diminished, the capacity of the venous bed increased and the central blood volume, cardiac output, and left ventricular work fell. However, it would appear likely from the observations of Alexander (22), that when venous tone diminishes, for any given increment in venous blood volume the transmural venous pressure rises to a greater extent than when the venous bed is initially partially constricted. This would permit a larger fraction of the infused blood to enter the thorax and cardiac output to rise significantly. The concept that even small changes in venous tone may induce striking changes in cardiac output has previously been stressed by Folkow (29).

Pertinent to this possible explanation of the data obtained are those studies which have demonstrated that venous tone in man is not constant, but may be altered by a variety of stimuli (30-34). In particular, ganglionic blockade produces venodilatation in patients in congestive heart failure $(35,36)$ and in normal subjects during muscular exercise (34). The experiments of Freis and associates have also suggested that hexamethonium blocks reflex venoconstriction in normal subjects (37). These workers demonstrated that phlebotomies of 250 to $500 \mathrm{ml}$ resulted in a striking decline in arterial pressure only after the administration of hexamethonium. This would appear to be analogous to the observation (Figure 4 ) that a greater elevation of arterial pressure occurs when blood was infused in the presence of the Arfonad infusion than in its absence.

Although the subjects were mildly anemic in the present study, whole blood was utilized instead of saline, dextran, plasma or albumin in order to avoid any acute change in the hematocrit. It has been demonstrated clearly in anesthetized dogs that acute depression of the hematocrit by the dilution resulting from large intravenous infusions of fluid, rather than from hypervolemia per se, may be responsible for the elevation in cardiac output noted when hemodilution occurs $(38-40)$. 
Although there was a significant lowering of hematocrit by the phlebotomies prior to the initial study, there were no striking differences between the hematocrits at the beginning and completion of each transfusion, nor between those obtained in the course of the first and second studies. The direct effects of partial ganglionic blockade on myocardial function are not considered likely to account for the experimental results obtained, since it has been demonstrated (41) that hexamethonium actually depresses myocardial contractility.

Experiments in which hypervolemia is induced acutely in intact human subjects may not be ideally suited for determining the applicability of Starling's law of the heart to man. The presence of an intact autonomic nervous system results in failure of a significant fraction of the infused fluids to augment the volume of blood within the heart and lungs, and the stimulation of myocardial contraction provided by an increased end-diastolic fiber length cannot result (42). Starling's law of the heart in man may, perhaps, be examined more profitably by studying the relationship between ventricular filling pressure or fiber length and ventricular stroke work under conditions in which significant variations in filling are induced. Such studies are now in progress.

\section{SUMMARY}

1. The cardiovascular response to transfusion in the absence and presence of Arfonad has been studied in seven human subjects with normal cardiovascular systems.

2. Transfusion in the control state produced no significant change in central blood volume, an average elevation of cardiac output of $0.50 \pm$ $1.37 \mathrm{~L}$ per minute and of left ventricular stroke work of $23.3 \pm 33.8 \mathrm{~g}-\mathrm{m}$. The increase in each of these parameters resulting from transfusion during partial ganglionic blockade was substantially greater and averaged $348 \pm 188 \mathrm{ml}, 2.40 \pm$ $0.61 \mathrm{~L}$ per minute, and $73.3 \pm 25.7 \mathrm{~g}-\mathrm{m}$, respectively.

3. It is suggested that when hypervolemia is induced acutely in intact man marked alterations in circulatory dynamics are prevented by the activity of the autonomic nervous system, which results in reflex venodilatation and depression of myocardial contractility. Accordingly, Starling's law of the heart cannot be readily demonstrated. When hypervolemia is induced after the activity of the autonomic nervous system has been reduced, more striking hemodynamic changes occur, resembling those noted in the Starling heartlung preparation when venous inflow is augmented.

\section{REFERENCES}

1. McMichael, J., and Sharpey-Schafer, E. P. Cardiac output in man by a direct Fick method. Effects of posture, venous pressure change, atropine and adrenaline. Brit. Heart J. 1944, 6, 33.

2. Warren, J. V., Brannon, E. S., Weens, H. S., and Stead, E. A., Jr. Effect of increasing the blood volume and right atrial pressure on the circulation of normal subjects by intravenous infusions. Amer. J. Med. 1948, 4, 193.

3. Doyle, J. T., Wilson, J. S., Estes, E. H., and Warren, J. V. The effect of intravenous infusions of physiologic saline solution on the pulmonary arterial and pulmonary capillary pressure in man. J. clin. Invest. 1951, 30, 345.

4. Schnabel, T. G., Jr., Eliasch, H., Thomasson, B., and Werkö, L. The effect of experimentally induced hypervolemia on cardiac function in normal subjects and patients with mitral stenosis. J. clin. Invest. 1959, 38, 117.

5. Witham, A. C., Fleming, J. W., and Bloom, W. L. The effect of intravenous administration of dextran on cardiac output and other circulatory dynamics. J. clin. Invest. 1951, 30, 897.

6. Fleming, J. W., and Bloom, W. L. Further observations on the hemodynamic effect of plasma volume expansion by dextran. J. clin. Invest. 1957, 36, 1233.

7. Stead, E. A., Jr., Brannon, E. S., Merrill, A. J., and Warren, J. V. Concentrated human albumin in the treatment of shock. Arch. intern. Med. 1946, 77, 564.

8. Randall, L. O., Peterson, W. G., and Lehmann, G. The ganglionic blocking action of thiophanium derivatives. J. Pharmacol. exp. Ther. 1949, 97, 48.

9. McCubbin, J. W., and Page, I. H. Nature of the hypotensive action of a thiophanium derivative (RO 2-2222) in dogs. J. Pharmacol. exp. Ther. 1952, 105, 437.

10. Hamilton, W. F., Moore, J. W., Kinsman, J. M., and Spurling, R. G. Studies on the circulation. IV. Further analysis of the injection method and of changes in hemodynamics under physiological and pathological conditions. Amer. J. Physiol. 1932, 99, 534.

11. Shadle, O. W., Ferguson, T. B., Gregg, D. E., and Gilford, S. R. Evaluation of a new cuvette densi- 
tometer for determination of cardiac output. Circulat. Res. 1953, 1, 200.

12. Gilford, S. R., Gregg, D. E., Shadle, O. W., Ferguson, T. B., and Marzetta, L. An improved cuvette densitometer for cardiac output determination by the dye-dilution method. Rev. Scient. Inst. 1953, 24, 696.

13. Sabiston, D. C., Jr., Khouri, E. M., and Gregg, D. E. Use and application of the cuvette densitometer as an oximeter. Circulat. Res. 1957, 5, 125.

14. Braunwald, E., Fishman, A. P., and Cournand, A. Estimation of the volume of a circulatory model by the Hamilton and Bradley methods at varying flow volume ratios. J. appl. Physiol. 1958, 12, 445.

15. Braunwald, E., Binion, J. T., Morgan, W. L., Jr., and Sarnoff, S. J. Alterations in central blood volume and cardiac output induced by positive pressure breathing and counteracted by Metaraminol (Aramine). Circulat. Res. 1957, 5, 670.

16. Warren, J. V., Brannon, E. S., Stead, E. A., Jr., and Merrill, A. J. The effect of venesection and pooling of blood in the extremities on the atrial pressure and cardiac output in normal subjects with observations on acute circulatory collapse in three instances. J. clin. Invest. 1945, 24, 337.

17. Milnor, W. R., and Bertrand, C. A. Estimation of venous blood volume in the $\operatorname{dog}$ by the indicatordilution method. Circulat. Res. 1958, 6, 55.

18. Sjöstrand, T. The regulation of the blood distribution in man. Acta physiol. scand. 1952, 26, 312.

19. Warren, J. V., Weissler, A. M., and Leonard, J. J. Observations on the determinants of cardiac output. Trans. Ass. Amer. Phycns 1957, 70, 268.

20. Heymans, C., and Neil, E. Reflexogenic Areas of the Cardiovascular System. Boston, Little, Brown and Company, 1958.

21. Alexander, R. S. Reflex alterations in venomotor tone produced by venous congestion. Circulat. Res. 1956, 4, 49.

22. Alexander, R. S. The participation of the venomotor system in pressor reflexes. Circulat. Res. 1954, 2, 405.

23. Salzman, E. W. Reflex peripheral venoconstriction induced by carotid occlusion. Circulat. Res. 1957, 5, 149.

24. Sarnoff, S. J. Some physiologic considerations in the genesis of acute pulmonary edema in Pulmonary Circulation, W. R. Adams and I. Veith, Eds. New York, Grune and Stratton, 1959, pp. 273-282.

25. Rashkind, W. J., Lewis, D. H., Henderson, J. B., Heiman, D. F., and Dietrick, R. B. Venous return as affected by cardiac output and total peripheral resistance. Amer. J. Physiol. 1953, 175, 415.

26. Daly, M. deB., and Luck, C. P. The effects of carotid sinus baroreceptor reflexes on pulmonary arterial pressure and pulmonary blood flow in the dog. J. Physiol. 1958, 143, 343.

27. Sarnoff, S. J., Brockman, S. K., Gilmore, J. P., Mitchell, J., and Linden, R. J. The influence of carotid sinus pressure on myocardial contractility. Fed. Proc. 1959, 18, 137.

28. Brockman, S. K., Linden, R. J., Mitchel, J., Gilmore, J. P., and Sarnoff, S. J. The effect of vagal stimulation on ventricular function. Fed. Proc. 1959, 18, 17.

29. Folkow, B. Nervous control of the blood vessels. Physiol. Rev. 1955, 35, 629.

30. Wood, J. E., Litter, J., and Wilkins, R. W. Peripheral venoconstriction in human congestive heart failure. Circulation 1956, 13, 524.

31. Wood, J. E., and Eckstein, J. W. A tandem forearm plethysmograph for study of acute responses of the peripheral veins of man: The effect of environmental and local temperature change, and the effect of pooling blood in the extremities. J. clin. Invest. 1958, 37, 41.

32. Eckstein, J. W., Hamilton, W. K., and McCammond, J. M. Pressure-volume changes in the forearm veins of man during hyperventilation. J. clin. Invest. 1958, 37, 956.

33. Eckstein, J. W., and Hamilton, W. K. The effects of isoproterenol on peripheral venous tone and transmural right atrial pressure in man. $\mathrm{J}$. clin. Invest. 1959, 38, 342.

34. Merritt, F. L., and Weissler, A. M. Reflex venomotor alterations during exercise and hyperventilation. Amer. Heart J. 1959, 58, 382.

35. Burch, G. E., and Murtadha, M. A study of the venomotor tone in a short intact venous segment of the forearm of man. Amer. Heart J. 1956, 51, 807.

36. Burch, G. E. A method for measuring venous tone in digital veins of intact man. A.M.A. Arch. intern. Med. 1954, 94, 724.

37. Freis, E. D., Stanton, J. R., Finnerty, F. A., Schnaper, H. W., Johnson, R. L., Rath, C. E., and Wilkins, $\mathrm{R}$. W. The collapse produced by venous congestion of the extremities or by venesection following certain hypotensive agents. J. clin. Invest. 1951, $30,435$.

38. Sunahara, F. A., and Beck, L. Cardiovascular effect of acutely produced anemia in the normal dog. Amer. J. Physiol. 1954, 176, 139.

39. Sunahara, F. A., Hatcher, J. D., Beck, L., and Gowdly, C. W. Cardiovascular responses in dogs to intravenous infusions of whole blood, plasma, and plasma followed by packed erythrocytes. Canad. J. Biochem 1955, 33, 349.

40. Fowler, N. O., Bloom, W. L., and Ward, J. A. Hemodynamic effects of hypervolemia with and without anemia. Circulat. Res. 1958, 6, 163.

41. Cotten, M. deV., Brown, J. M., and Kronen, P. S. Heart force responses to pressor amines during hypotension produced by hexamethonium. Anesthesiology 1954, 15, 126.

42. Starling, E. H. The Linacre Lecture on the Law of the Heart (Cambridge, 1915). London, Longmans, Green and Company, 1918. 